\title{
Sinopse da tribo Alchorneae (Euphorbiaceae) no Estado de São Paulo, Brasil
}

\author{
Rafaela Freitas dos Santos ${ }^{1,3}$ e Maria Beatriz Rossi Caruzo ${ }^{2}$
}

Recebido: 18.03.2014; aceito: 22.10 .2014

\begin{abstract}
Synopsis of the tribe Alchorneae (Euphorbiaceae) in São Paulo State, Brazil). Two genera, Aparisthmium, a monotypic genus, and Alchornea, with three species, were recognized for the tribe Alchorneae in the State of São Paulo. Keys for genera and species, information about phenology, geographic distribution, vegetation of occurrence, and taxonomic comments are provided to each species.
\end{abstract}

Keywords: Alchornea, Aparisthmium, Taxonomy

RESUMO - (Sinopse da tribo Alchorneae (Euphorbiaceae) no Estado de São Paulo, Brasil). A tribo Alchorneae está representada no Estado de São Paulo pelos gêneros Aparisthmium, monotípico, e Alchornea, com três espécies. São apresentadas chaves de identificação para os gêneros e espécies, informações sobre fenofases, distribuição geográfica, vegetação de ocorrência e comentários taxonômicos sobre as espécies.

Palavras-chave: Alchornea, Aparisthmium, Taxonomia

\section{Introdução}

Euphorbiaceae Juss. é uma das maiores famílias de Malpighiales (Wurdack \& Davis 2009), com cerca de 250 gêneros e aproximadamente 6.300 espécies (números estimados a partir de Govaerts et al. 2000) distribuídas em todas as regiões do mundo, principalmente em áreas tropicais (Radcliffe-Smith 2001). No Brasil são reconhecidos 63 gêneros e 917 espécies pertencentes à família (Cordeiro et al. 2013), que podem ser encontradas em todos os domínios fitogeográficos do país. Segundo Caruzo \& Cordeiro (2007), no Estado de São Paulo a família está representada por 37 gêneros e 160 espécies.

A tribo Alchorneae (Hurus.) Hutch. pertence a subfamília Acalyphoideae s.s. (Wurdack et al. 2005) e é caracterizada pelo indumento de tricomas simples ou estrelados, folhas frequentemente glandulosas, flores monoclamídeas, estiletes inteiros ou bífidos, estames 4-60 e inflorescência estaminada axilar ou terminal (Secco 2004). A tribo, de acordo com a circunscrição de Secco (2004), é formada pelas subtribos Alchorneinae Hurus que possui distribuição pantropical e pelos gêneros Orfilea Baill., Bossera Leandri, Alchornea Sw., Caelebogyne J.Sm, Aparisthmium (A. Juss.)
Baill. e Bocquillonia Baill. (Webster 1994, RadcliffeSmith 2001); e pela subtribo Conceveibinae Webster, que possui distribuição neotropical e é constituída pelo gênero Conceveiba Aubl. (Secco 2004).

No Estado de São Paulo ocorrem dois gêneros da tribo: Alchornea e Aparisthmium. Alchornea, com 41 espécies, ocorre na Ásia, África, Malásia, Madagascar, Antilhas, América Central e América do Sul. Na região Neotropical, onde seus centros de diversidade estão localizados no Peru e Brasil, suas espécies arbóreas e arbustivas são encontradas em florestas e cerrados (Secco 2004). Aparisthmium, gênero com uma única espécie de hábito arbustivo a arbóreo, Aparisthmium cordatum (A.Juss.) Baill., é amplamente distribuído em formações florestais desde o sul da América Central até a América do Sul (Secco 2004). No Estado de São Paulo, as espécies crescem em florestas ombrófilas e mesófilas, e cerrados.

\section{Material e métodos}

Opresente estudo foi baseado na análise morfológica de coleções do Estado de São Paulo depositadas nos herbários SP, SPF, SPSF, ESA, IAC e UEC (acrônimos segundo Thiers, continuously updated).

1. Instituto de Botânica de São Paulo, Núcleo de Pesquisas em Curadoria do Herbário, Caixa Postal 3005, 01061-970 São Paulo, SP, Brasil

2. Universidade Federal de São Paulo, Campus Diadema, Departamento de Ciências Exatas e da Terra, 09972-270 Diadema, SP, Brasil

3. Autor para correspondência: rafadbl@hotmail.com 
Para cada uma das espécies são referidos: publicação original, basiônimo (quando necessário), nomes populares compilados das etiquetas dos herbários (quando informados), distribuição geográfica, tipo de vegetação de ocorrência, um material selecionado por município e chave de identificação para os gêneros e espécies.

\section{Resultados e Discussão}

No Estado de São Paulo foram reconhecidas quatro espécies pertencentes à tribo Alchorneae: Alchornea glandulosa Poepp., A. sidifolia Müll.Arg., A. triplinervia (Spreng.) Müll.Arg. e Aparisthmium cordatum (A.Juss) Baill.

Chave para os gêneros da tribo Alchorneae ocorrentes no Estado de São Paulo

1. Folhas actinódromas, sem estipelas na base. Estames 8, patentes. Ovário 2-carpelar. Estiletes 2. Sementes com testa discretamente rugosa, não pintalgada Alchornea

2. Folhas peninérveas, com estipelas na base. Estames 4, eretos. Ovário 3-carpelar. Estiletes 3. Sementes com testa lisa, pintalgada. Aparisthmium

1. Alchornea Sw., Prodr. 6: 98. 1788.

Árvores a arbustos dioicos, raramente monoicos, com indumento de tricomas estrelados. Folhas simples, inteiras, pecioladas; actinódromas; margens crenadas a serreadas; glândulas maculares na base e domácias de tricomas entre as nervuras; estípula caduca ou obsoleta. Inflorescências estaminadas espiciformes e ramificadas, as pistiladas em racemos. Flores monoclamídeas, as estaminadas em glomérulos, as pistiladas geralmente isoladas; cálice 2-3(-4)-lobado; estames ca. 8, conados na base, patentes, filetes subulados, anteras rimosas; flores pistiladas com cálice (3-)4(-6)-lobado; ovário 2(-3)-locular; estiletes 2(-3), inteiros ou raramente bífidos no ápice. Fruto cápsula loculicida 2(-3)-carpelar; sementes subglobosas, ecarunculadas, vermelhas.

Chave de identificação para as espécies de Alchornea do Estado de São Paulo

1. Folhas com (2-)3(-4) pares de nervuras secundárias, pecíolo canaliculado. Raque da inflorescência estaminada canaliculada; flores pistiladas pediceladas ......... 3. A. triplinervia

1. Folhas com 5(-6) pares de nervuras secundárias, pecíolo cilíndrico. Raque da inflorescência estaminada cilíndrica; flores pistiladas sésseis.
2. Lâmina foliar levemente deflexa, face adaxial e abaxial pubescente a glabrescente. Flores pistiladas com lobos das sepálas de 1,5-2 mm compr. ............. 1. A. glandulosa

2. Lâmina foliar fortemente deflexa, face adaxial pubescente e face abaxial velutina. Flores pistiladas com lobos da sepálas de 2-4 mm compr. ................... 2.A. sidifolia

1. Alchornea glandulosa Poepp., Nov. Gen. Sp. Pl. 3: 18, pl. 221. 1841. Tipo: PERU. MAYNAS, s.d., Poeppig 2198 (lectótipo W, designado por Secco [2004]; isolectótipos F, G).

Figuras 1a-c

Árvores ou arbustos dioicos, raramente monoicos; 1,5-15 m alt.; indumento de tricomas estrelados; ramos pubescentes a glabrescentes. Folhas actinódromas basais, com 3 nervuras principais, a central com 5(-6) nervuras secundarias; estípulas caducas ou ausentes; pecíolo cilindrico, pubescente, $1,5-11 \mathrm{~cm}$ compr.; lâmina 6-18 × 4,5-14 cm, levemente deflexa, ovalada, orbicular, obovada ou elíptica, cartácea, margem serreada e ciliada, ápice acuminado, cuspidado, agudo, cuneado ou arredondado, base arredondada, face adaxial pubescente a glabrescente, tricomas concentrados nas nervuras, face abaxial glabrescente ou pubescente; glândulas (1-)3-6(-10) no limbo e/ ou na base; domácias de tricomas entre a nervura central e as secundárias. Inflorescência estaminada em panícula, axilar ou terminal, 6-12 cm compr.; raque cilíndrica; flores estaminadas pediceladas, pedicelo 0,5-1 mm compr.; cálice gamossépalo 2(-3)-lobado, ca. $2 \mathrm{~mm}$ compr., glabros, estames formando estrutura discóide. Inflorescência pistilada em espiga; terminal ou axilar, raramente caulinar, 1,5-14 cm compr.; flores pistiladas solitárias e sésseis, cálice 4-lobado, lobos 1,5-2 mm compr., tomentosos; ovário subgloboso, pubescente, 1,5-2 × 1-2 mm, 2-locular; estiletes 2, glabros internamente e piloso externamente. Fruto $0,5-0,7 \times 0,3-0,8 \mathrm{~cm}$, pubescente, liso a levemente rugoso; sementes 1-2(-3), ca. $0,5 \times 0,5 \mathrm{~cm}$, arredondadas a ovais, levemente muricadas, crustáceas e vermelhas.

Árvore a arbusto com ampla distribuição nas florestas úmidas da América do Sul e Central, Ocorre no Panamá, Costa Rica, Colômbia, Venezuela, Peru, Equador, Bolívia, Argentina, Paraguai e em todas as regiões do Brasil (Secco 2004). No Estado de São Paulo é encontrada em florestas ombrófilas e mesófilas, restingas e matas ciliares. Foi coletada com flores de abril a agosto e com frutos de junho a outubro. 

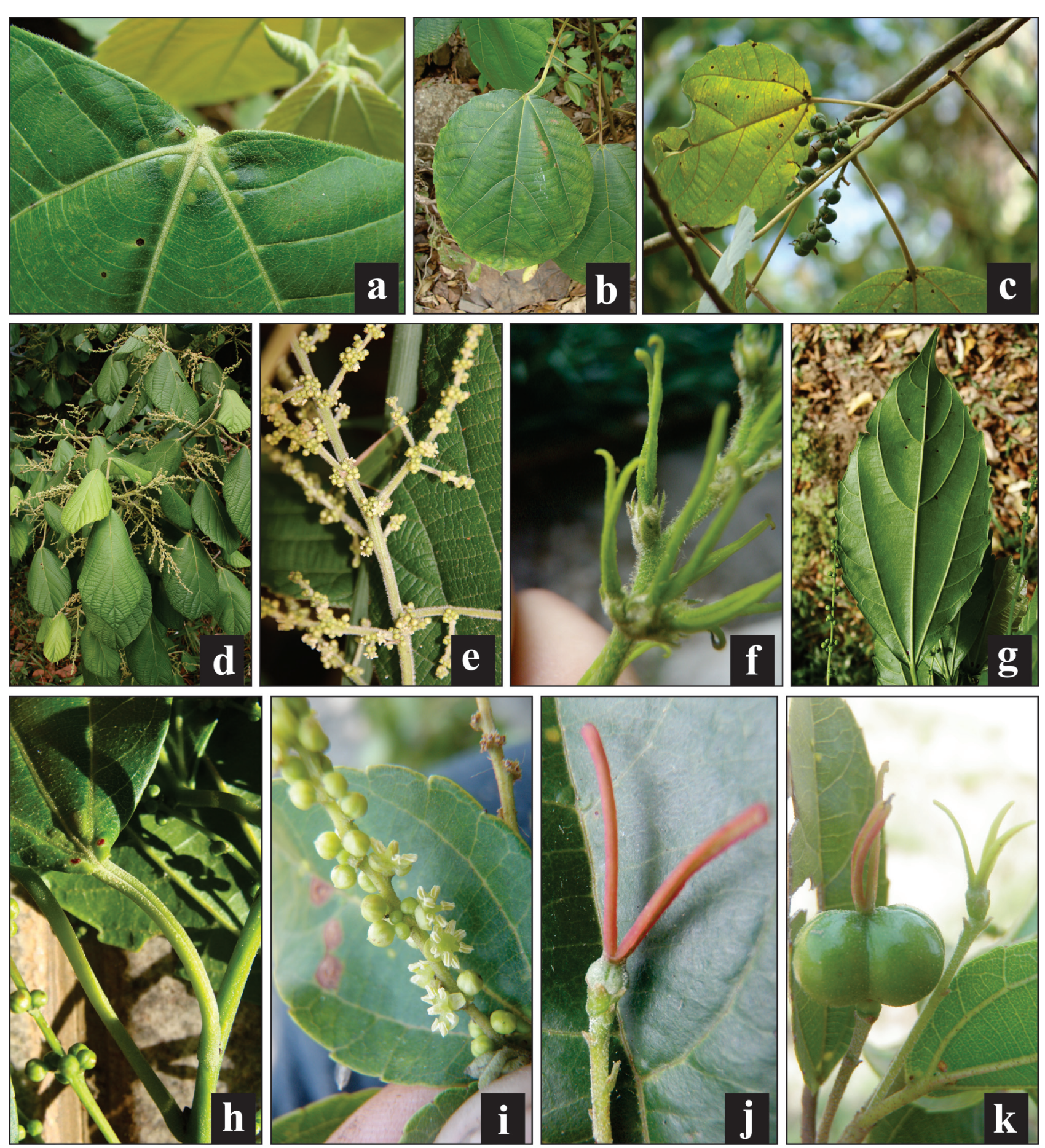

Figura 1. Espécies de Alchornea ocorrentes no Estado de São Paulo, Brasil. a. detalhe da folha de A. glandulosa, evidenciando as glândulas na base da lâmina foliar. b. folha de $A$. glandulosa. c. ramo de $A$. glandulosa com frutos imaturos. d. ramo de $A$. sidifolia com as folhas deflexas e inflorescências estaminadas. e. ramo com inflorêscencia estaminada de $A$. sidifolia. f. flores pistiladas de $A$. sidifolia. g. folha de A. triplinervia. h. pecíolo canaliculado de $A$. triplinervia e glândulas da base do limbo. i. detalhe da inflorêscencia estaminada de $A$. triplinervia com flores em antese. j. flor pistilada de A. triplinervia. k. fruto imaturo de A. triplinervia com dois carpelos. (Fotografias. a-h. R.F. Santos; i-k. O.L.M. Silva).

Figure 1. Alchornea species from São Paulo. a. detail of A. glandulosa leaf, showing the basal foliar glands. b. detail of $A$. glandulosa leaf, showing 4-5 secondary veins. c. branch of $A$. glandulosa, with immature fruits. d. branch of $A$. sidifolia showing deflexed leaves and staminate flowers. e. detail of staminate inflorescence rachis of $A$. sidifolia. f. pistillate flowers of $A$. sidifolia. g. leaf of $A$. triplinervia showing 2-3 secondary veins. h. canaliculate petiole of $A$. triplinervia. i. detail of staminate inflorescence in $A$. triplinervia. j. pistillate flower of A. triplinervia. k. immature fruit of A. triplinervia showing two carpels. (Photos. a-h: R.F. Santos; i-k: O.L.M. Silva). 
Material examinado selecionado: BRASIL. S̃̃o Paulo: Amparo, Estrada de Ibiti, perto de Três Pontes, 25-VII-1946, M. Kuhlmann \& E. Kuhn 1381 (SP), Anhembi, Fazenda Barreto Rico, várzea do Rio Piracicaba, 6-X-1956, M. Kuhlmann 3985 (SP). Bauru, Jardim Botânico de Bauru, 26-VII-1977, M.H. Ongaro Pinheiro 375 (SP, HRCB). Campinas, VI-1919, J. Campos Novaes 1556 (SP). Cananéia, Parque Estadual da Ilha do Cardoso, estrada para a turbina, 13-IX-1990, F. Barros 1925 (SP, MG, UEC). Eldorado, Parque Estadual de Jacuoiranga, beira da Estrada de Eldorado para a Caverna do Diabo, 18-V-1994, I. Cordeiro \& M.A.B. Barros 1457 (SP, UEC, SPF, PMSP). Jaboticabal, Fazenda Santa Izabel, margem esquerda do Rio Mogi-Guaçu, 24-IV-1995, E.H.A. Rodrigues 303 (SP). Lençois Paulistas, estrada de Terra, Lençóis Paulista - Água de Santa Barbara, 12-VI-1995, J.Y. Tamashiro et al. 114 (SP, SPF, HRCB). Mogi-Guaçu, Martinho Prado Júnior, Fazenda Campininha, 19-IX-1988, I.Y.A. Ludeewings 42 (SP). Pariquera-Açu, propriedade de Antonio Povinski, 31-V-1996, N.M. Ivanauskas 801 (SP, ESA). Porto Ferreira, Parque Estadual, 31-VII-1997, J.E.A. Bertoni 502 (SP, SPSF). Santos, VIII-1915, H. Luederwaldt 6419 (SP). São Vicente, Parque Estadual Xixová-Japuí, Região de Paranapuã em mata atras do CECOF, margem do córrego, 22-VI-2001, J.A. Pastore \& C. Moura 1035 (SP, SPSF). Timburi, Fazenda Domiciana, 14-VI-1995, J.Y. Tamashiro et al 1278 (SP, SPF, HRCB, ESA, PMSP). Ubatuba, Picinguaba, estrada da casa da Farinha, 8-X-1988, N.M.L. Cunha et al. 145 (SP).

2. Alchornea sidifolia Müll.Arg., Linnaea 34: 169. 1865. Tipo: BRASIL. Brasilia meridionali, s.d., Sellow s.n. (lectótipo G, designado por Secco [2004]; isolectótipos $\mathrm{GH}, \mathrm{K}$ !, P).

Figuras 1d-f

Nomes populares: tapiá, iricurana, tapiá-guaçu e tapiá-iricurana.

Arbustos ou árvores dióicos; 3-14 m alt.; indumento de tricomas estrelados, ramos densamente velutinos. Folhas actinódromas basais à suprabasais, com 3 nervuras principais, a central com 5(-6) nervuras secundárias; estípula ausente ou caduca; pecíolo cilíndrico, denso velutino, $2-19 \mathrm{~cm}$ compr.; lâmina 6-25 × 6-23 cm, deflexa, oblonga, cordada, ovalada, orbicular ou elíptica, cartácea, margem serreada e ciliada, ápice cordado, cuspidado, cuneado, retuso, mucronado ou arredondado, base curvex, arredondada ou emarginada, face adaxial pubescente, face abaxial velutina; glândulas $9(-28)$ na base; domácias obstruídas. Inflorescência estaminada em panícula, axilar, 17-25 cm compr.; raque cilíndrica; flores estaminadas pediceladas, pedicelo 1-3 mm; cálice 2-4-lobado glabrescente a glabro; estames (6-)8(-13) formando estrutura discóide. Inflorescência pistilada em espiga ou panícula, axilar, 5,5-16 cm compr.; flores pistiladas sésseis; cálice gamossépalo, com lobos recobrindo o ovário, 4-lobado, 2-4 mm compr., tomentoso; ovário subgloboso, tomentoso, 0,8-1,5 × 1,5-2 mm, 2-3-locular; estiletes 2(-3), glabros internamente e pilosos externamente. Fruto 0,5-1 $\times 0,6-0,8 \mathrm{~cm}$, pubescente, rugoso; sementes (1-)2, ca. $0,5 \times 0,5 \mathrm{~mm}$, ovais, levemente muricadas, crustáceas e vermelhas.

Arbusto a árvore com distribuição restrita ao Sudeste e Sul do Brasil e Argentina (Secco, 2004). Espécie muito comum na Mata Atlântica do Estado de São Paulo, em planícies litorâneas e no planalto, onde ocorre principalmente em florestas secundárias, capoeiras e beiras de mata. Foi coletada com flores de setembro a dezembro e com frutos em novembro.

Material examinado selecionado: BRASIL. São PAUlo: Cunha, Estação Experimental da Serra do Mar, Trilha da bacia experimental, Beira de estrada ao longo do Rio Paraibuna, 14-XII-1996, A.R. Ferreti et al. 80 (SP). Mogi das Cruzes, Fazenda Parataí, na mata, 30-XI-1943, B. Pickel s.n. (SP 296592, SPSF). São Paulo, Parque Estadual das Fontes do Ipiranga, Instituto de Botânica. Trilha atrás dos prédios centrais, 1-XI-2001, M.B.R. Caruzo \& I. Cordeiro 3 (SP). Ubatuba, Instituto Agrônomico, XI-1993, M.D. de Moraes et al. 128 (SP, SPF).

3. Alchornea triplinervia (Spreng.) Müll.Arg., Prodr. 15(2): 909. 1865. Antidesma triplinervium Spreng., Neue Entdeck. Pflanzenk. 2: 116. 1821. Tipo: BRASIL. RIO DE JANEIRO: Serra do Mar, s.d., Gardner 617 (neótipo $\mathrm{G}$, designado por Webster \& Huft [1988]; isótipos BM, GH!, P, W).

Figuras 1g-k

Nomes populares: tapiá, tapiá-vermelho, caixeta e tapiá-mirim.

Árvores dioicas; (3-)5-8(-15) m alt.; indumento de tricomas estrelados, ramos grabrescentes a glabros. Folhas actinódromas suprabasais, 3 nervuras principais, a central com 2-3 pares de nervuras secundárias; estipulas ausentes ou caducas; pecíolo canaliculado, avermelhado, quando jovem, grabro a 
glabrescente, raramente pubescente, 0,5-6 cm compr.; lâmina 2-13 × 1-7,5 cm, elíptica, obovada, oval, lanceolada a orbicular, cartácea, margem serreada a esparsamente serreada, ápice longamente acuminado, arredondado, mucronado ou agudo, raramente emarginado, base arredondada ou cuneada, face adaxial glabra ou glabrescente com tricomas concentrados nas nervuras, face abaxial esparsamente pubescente ou glabrescente; glândulas 1-3, vermelhas e brilhantes na base e/ou no limbo; domácias crateriformes entre nervura central e nervura secundária. Inflorescência estaminada em panícula ou racemo, axilar, raro terminal, 3-14 cm compr.; raque canaliculada; flores estaminadas pediceladas, pedicelos articulados, 0,5-2 mm compr., cálice 2-lobado, estames formando estrutura discoide. Inflorescência pistilada em racemo, axilar, 6-10 cm compr.; flores pistiladas pediceladas, pedicelos 0,5-1 cm compr., cálice (3-)4-lobado, ca. $3 \mathrm{~mm}$, lobos pubescentes; ovário piriforme, pubescente, 1,5-3 × 1-2 mm, 2-3-locular, estiletes 2(-3), glabros internamente e piloso externamente. Fruto $0,8-0,6 \times$ ca. $1,0 \mathrm{~cm}$, pubescente a glabrescente, rugoso; sementes $2(-3)$, ca. $0,5 \times 0,5 \mathrm{~cm}$, globosas a subglobosas, levemente muricadas, crustáceas e vermelhas.

Árvore com ampla distribuição em florestas e cerrados da América Central e do Sul e em todas as regiões do Brasil (Secco 2004). Em São Paulo é encontrada em florestas ombrófilas e mesófilas do planalto, das planícies costeiras e encostas da Serra do Mar e matas ciliares. Foi coletada com flores em outubro e novembro, e com frutos de dezembro a março.

Material examinado selecionado: BRASIL. São PAUlo: Amparo, Monte Alegre, Sitio do Recreio, 9-XII-1943, M. Kuhlmann 1126 (SP). Angatuba, Estação Ecológica de Angatuba-estrada de terra a oeste do Centro Administrativo da UC. 18-XII-2012 O.L.M. Silva 44 (SP, SPF). Bananal, Estação Ecológica de Bananal, 21-XI-2008, R.T.Polisel et al. 900 (SPSF, UEC). Bom Sucesso de Itararé, estrada ItararéBonsucesso, ca. $500 \mathrm{~m}$ abaixo da bifurcação para a Fazenda São Nicolau, 30-X-1993, Souza, V.C. 4544 (SP, SPF). Brotas, Fazenda Nego Boaval, 13-IV-1993, L.C. Bernacci et al. 35033 (UEC). Botucatu, Rubião Junior, Mata Butignolli, 2-X-1980, I.C. Izatto 8 (SP, MG). Cananéia, Parque Estadual da Ilha do Cardoso, Praia de Ipanema, 3-XII-1985, F. Barros 1217 (SP, UEC, MG). Cassia dos Coqueiros, Sitio Nossa Senhora do Carmo, 9-XI-1994, A.M.G.A. Tozzi \& L.B. Sartori s.n. (SP 296937, UEC, SPF, ESA, HRCB). Cunha, Estação Experimental da Serra do Mar, Nucleo Cunha, Trilha do Rio Bonito, 11-XII-1996, A. Ferreti et al. 17 (SP). Iguape, Morro das Pedras, XII-1917, A.C. Brade 7897 (SP). Iporanga, 26-I-1994, K.D. Barreto et al. 1906 (SP). Itanhaém, Estrada entre o Biarro de Suarão e a Fazenda São Luiz, 7-X-1995, V.C. Souza \& J.P. Souza 9191 (SP). Mogi das Cruzes, Parque municipal da Serra do Itapety, 12-VII-1990, P.L.B. Tomasulo 17 (SP). Mogi Guaçu, Martinho Prado Júnior, Fazenda Campininha, Mata do Português, VII-1987, I.Y.A. Ludewigs s.n. (SP 248515). Peruíbe, Reserva da Juréia, Praia da Juréia, 16-III-1990, I. Cordeiro et al. 560 (SP, SPSF). Salesópolis, Estação Biológica de Boracéia, Perto das margens do Rio Coruja, 27-IV-1966, J.R. Mattos 13511 (SP). São Paulo, Parque Estadual das Fontes do Ipiranga, Instituto de Botânica, 23-XI-1998, I. Cordeiro et al. 1773 (SP). Teodoro Sampaio, Reserva de Teodoro Sampaio, 10-III-1981, C.F.S. Muniz 262 (SP). Ubatuba, Picinguaba, 2-II-1996, H.F. Leitão-Filho et al. 34781 (SP, UEC).

2. Aparisthmium Endl., Gen. Plan. 1112. 1840.

Árvores ou arvoretas dióicas, com indumento de tricomas simples. Folhas simples, inteiras, pecioladas, com estipelas cônicas, estípula caducas ou obsoletas, peninérveas, margens serreadas, face abaxial frequentemente com glândulas maculares na base. Inflorescências estaminadas espiciformes, simples ou ramificadas, as pistiladas em racemos; flores estaminadas monoclamídeas, curtamente pediceladas, dispostas em glomérulos; cálice 3-lobado, valvar, estames 4, conados na base, anteras com deiscência lateral, rimosas; flores pistiladas solitárias, monoclamídeas, pediceladas; cálice 5-lobado ovário 3-locular, estiletes-3, 2-fidos. Fruto cápsula, 3-carpelar; sementes elípticas, pintalgadas, ecarunculadas.

1. Aparisthmium cordatum (A.Juss.) Baill., Adansonia 5: 307. 1865. Conceveiba cordata A.Juss., Euphorb. Gen. 43, t.13, f.42a. 1824. Tipo: GUIANA. s.loc., s.d., Richard s.n. (holótipo P!).

Árvores ou arvoretas; 3-14 m alt.; ramos estriados à levemente estriados, cilíndricos, pubescentes a glabrescentes. Folhas peninérveas; pecíolo 2-10-(15) cm compr., levemente canaliculado ou inteiro, mais espesso da base até cerca de $1 \mathrm{~cm}$ do limbo; estipelas $0,5-7 \mathrm{~mm}$ compr., apicais, lanceoladas; lâmina (3)-9,5-28 × (2,5)-4-19,5 cm, 
elíptica a orbicular, cartácea, ápice caudado, cuspidado, arredondado ou raro agudo, base arredondada, levemente cuneada ou levemente truncada, face adaxial esparsamente pubescente, glabrescente a quase glabra, face abaxial pubescente a esparsamente pubescente; glândulas 2, na base. Inflorescências axilares ou terminais, (3)-12,5-35 cm compr.. Flores estaminadas pediceladas, pedicelos ca. $0,5 \mathrm{~mm}$ compr., geralmente com uma glândula na base; cálice 3(-4)-lobado, 1,5-2 mm compr., piloso no ápice, glabro internamente; (2-)3-4 estames, 1,5-3 mm compr.. Flores pistiladas pediceladas, pedicelo 0,6-1,5 cm compr., canaliculado, pubescente; bractéolas 2 externas e 1 interna, (1-) $2 \times$ ca. $1 \mathrm{~mm}$, externamente pubescentes e internamente glabras, com 1-2 glândulas na margem; cálice 4-lobado, 2 lobos externos e 2 internos, ca. 1,5 $\times 0,5 \mathrm{~mm}$, externamente pubescentes e internamente glabros; ovário pubescente a densamente pubescente, estiletes achatados, bífidos, 2-5 $\mathrm{mm}$, papiloso e glabro internamente, esparsamente pubescente externamente. Fruto 0,8-1 cm compr., glabrescente, liso a levemente rugoso; sementes 5-6 6 ca. $4 \mathrm{~mm}$.

Árvore de ampla distribuição em florestas e savanas de toda a América do Sul e em todas as regiões do Brasil (Secco 2004). Em São Paulo é encontrada em florestas ombrófilas e mesófilas, sendo muito comum nas florestas da planície litorânea. Foi coletada com flores de outubro a dezembro e com frutos de novembro a fevereiro.

Material examinado selecionado: BRASIL. SÃo PAULO: Anhembi, I.1982, Cesar et al. s.n (HRCB2409, UEC). Cananéia, X-1990, F. Barros 1829 (SP, MG, UEC). Cubatão, XII-1988, E.L. Silva 47 (SP, SPSF). Eldorado, II-1995, A. Sartori 32700 (SP, SPF, HRCB, PMSP). Iguape, XI-1990, E.L.M. Catharino et al. 1524 (SP, SPSF). Pariquera-Açu, XI-1968, H.F. Leitão Filho 628 (SP, IAC). Peruibe, X-1995, V.C. Souza et al. 9273 (SP, SPF, HRCB, PMSP). Pirapora do Bom Jesus, XII-1924, A. Gehrt s.n (SP12918). Rio das Pedras, II-1994, K.D. Barreto et al. 2004 (ESA). São José do Barreiro, XII-2007, H. Serafim 243 (SPF). Ubatuba, XII-1988, F.C.P. Garcia et al. 271 (SP, HRCB).

\section{Agradecimentos}

Ao Conselho Nacional de Desenvolvimento Cientifico e Tecnológico (CNPq), pela bolsa de Iniciação Científica concedida à primeira Autora; à Dra. Inês Cordeiro e ao Ms. Otavio Marques, pelo auxílio no decorrer do trabalho.

\section{Literatura citada}

Caruzo, M.B.R. \& Cordeiro, I. 2007. Sinopse da Tribo Crotoneae Dumort. (Euphorbiaceae s.s.) no Estado de São Paulo, Brasil. Hoehnea 34: 571-585.

Cordeiro, I., Secco, R., Cardiel, J.M., Steinmann, V., Caruzo, M.B.R., Riina, R., Lima, L.R., Maya-L., C.A., Berry, P., Carneiro-Torres, D.S., Silva, O.L.M., Sales, M.F.D., Silva, M.J., Sodré, R.C., Martins, M.L.L., Pscheidt, A.C., Athiê-Souza, S.M., Melo, A.L.D., Oliveira, L.S.D., Paula-Souza, J. 2013. Euphorbiaceae. In: Lista de Espécies da Flora do Brasil. Jardim Botânico do Rio de Janeiro. Disponível em: http://floradobrasil.jbrj.gov.br/jabot/floradobrasil/ FB113 (acesso em: 16-X-2013).

Govaerts, R., Frodin, D.G. \& Radcliff-Smith, A. 2000. World Checklist and Bibliography of Euphorbiaceae (and Pandaceae). v. 2. Royal Botanical Garden, pp. 1-32.

Radcliffe-Smith, A. 2001. Genera Euphorbiacearum. Royal Botanical Garden, Londres.

Secco, R. 2004. Alchorneae (Euphorbiaceae): (Alchornea, Aparisthmium e Conceveiba). Flora Neotropica 93: 1-195.

Thiers, B. [continuously updated]. Index Herbariorum: A global directory of public herbaria and associated staff. New York Botanical Garden's Virtual Herbarium. Disponível em http://sweetgum.nybg.org/ih/ (acesso em 10-II-2014).

Webster, G.L. 1994. Systematics of the Euphorbiaceae. Annals of the Missouri Botanical Garden. 81: 1-144.

Webster, G.L. \& Huft. M.J. 1988. Revised synopsis of Panamanian Euphorbiaceae. Annals of the Missouri Botanical Garden 75: 1087-1144.

Wurdack, K.J. \& Davis, C.C. 2009. Malpighiales phylogenetics: Gaining ground on one of the most recalcitrant clades in the angiosperm tree of life. American Journal of Botany 96: 1551-1570.

Wurdack, K.J., Hoffmann, P. \& Chase, M.W. 2005. Molecular phylogenetic analysis of uniovulate Euphorbiaceae (Euphorbiaceae sensu stricto) using plastid rbcL and trnL-F DNA sequences. American Journal of Botany 92: 1397-1420. 